\title{
Androgen receptor in cancer- associated fibroblasts influences stemness in cancer cells
}

\author{
Chun-Peng Liao', Leng-Ying Chen', Andrea Luethy', Youngsoo Kim², Kian Kani', \\ A Robert MacLeod ${ }^{2}$ and Mitchell E Gross ${ }^{1}$
}

${ }^{1}$ Lawrence J. Ellison Institute for Transformative Medicine, Keck School of Medicine, University of Southern California, Los Angeles, California, USA

2 Ionis Pharmaceuticals Inc., Carlsbad, California, USA

\begin{abstract}
Androgen receptor $(A R)$ regulation pathways are essential for supporting the growth and survival of prostate cancer cells. Recently, sub-populations of prostate cancer cells have been identified with stem cell features and are associated with the emergence of treatment-resistant prostate cancer. Here, we explored the function of AR in prostate cancer-associated fibroblasts (CAFs) relative to growth and stem cell-associated characteristics. CAFs were isolated from the murine $\mathrm{CPten}{ }^{-/-} \mathrm{L}$ prostate cancer model and cultured with human prostate cancer epithelial ( $\mathrm{hPCa}$ ) cells. A murine-specific AR antisense oligonucleotide (ASO) was used to suppress the expression of AR in the CAF cells. CAFs express low, but significant levels of AR relative to fibroblasts derived from non-malignant tissue. CAFs promoted growth and colony formation of hPCa cells, which was attenuated by the suppression of AR expression. Surprisingly, AR-depleted CAFs promoted increased stem cell marker expression in hPCa cells. Interferon gamma (IFN- $\gamma$ ) and macrophage colony-stimulating factor (M-CSF) were increased in AR-depleted CAF cells and exhibited similar effects on stem cell marker expression as seen in the CAF co-culture systems. Clinically, elevated IFN- $\gamma$ expression was found to correlate with histologic grade in primary prostate cancer samples. In summary, AR and androgendependent signaling are active in CAFs and exert significant effects on prostate cancer cells. IFN- $\gamma$ and M-CSF are AR-regulated factors secreted by CAF cells, which promote the expression of stem cell markers in prostate cancer epithelial cells. Understanding how CAFs and other constituents of stromal tissue react to anti-cancer therapies may provide insight into the development and progression of prostate cancer.
\end{abstract}

Correspondence should be addressed to M E Gross

Email mitchell.gross@usc.edu
Endocrine-Related Cancer (2017) 24, 157-170

\section{Introduction}

Androgen receptor (AR)-regulated pathways are critical for prostate cancer (PCa) cell proliferation and survival. AR-targeting therapies are a mainstay of treatment in prostate cancer based primarily on effects observed on cell growth, treatment resistance and metastasis in malignant

\author{
Key Words \\ - prostate cancer \\ - stroma \\ - cancer-associated fibroblast \\ - androgen receptor
}


of ductal morphogenesis during periods when epithelial AR expression is silenced (Cunha et al. 2004, Prins \& Putz 2008). In the post-natal period, AR expression in both stroma and epithelial compartments is required to complete the maturation of the prostate into a functional adult organ. Although epithelial cells express higher levels of AR, stromal AR is still essential to maintain the homeostasis between stromal and epithelial cells through the regulation of epithelial cell survival, proliferation, differentiation and regeneration (Kurita et al. 2001, Yu et al. 2012a).

Interactions between the stromal and epithelial compartments are important in the development of normal and malignant prostate tissue. Cancer-associated fibroblasts (CAFs) are the dominant cell type present in stromal tissue in cancer. Previous studies have shown that CAFs express functional AR and play a role in the development and progression of prostate cancer. For example, Niu and coworkers reported that stromal AR promotes the growth TRAMP and PC3 prostate cancer models (Niu et al. 2008). Lai and coworkers demonstrated that loss of stromal AR in the Pten ${ }^{+-}$mouse model led to a reduced incidence of prostatic intracellular neoplasia (PIN) as well as a decreased proliferation rate in non-malignant epithelial cells (Lai et al. 2012). Yu and coworkers demonstrated that knocking down AR in CAF cells led to decreased proliferation of normal, non-cancerous, prostate epithelium (Yu et al. 2012b). In contrast, clinical studies have shown decreased expression of stromal AR is associated with higher Gleason grade (Li et al. 2008) and an increased risk of relapse after radical prostatectomy (Henshall et al. 2001). Taken together, these studies support the importance of stromal AR in the development and progression of prostate cancer. However, the basis for tumor-promoting abilities of CAF on prostate cancer remains largely unexplored.

Standard androgen-deprivation therapy simultaneously targets both stromal and epithelial compartments, obscuring effects, which may be specific to one compartment or the other. Moreover, concurrently targeting epithelial and stromal compartments preclude study of the cross-talk between compartments, which may uncover novel therapeutic targets. Here, we used a mixed-species, co-culture system to specifically explore the effects of targeting the expression and function of AR in stromal cells. Decreased AR expression was achieved by co-incubation with a mouse-specific antisense oligonucleotide (ASO) to produce AR-depleted CAFs. Mouse CAFs increased the growth of human epithelial PCa cell lines, which was attenuated by co-incubation with AR-depleted CAFs.
Interestingly, the expression of several stem cell marker genes was upregulated in PCa cells grown with ARdepleted CAFs. Further, interferon gamma (IFN- $\gamma$ ) and macrophage colony-stimulating factor (M-CSF) were identified as secreted by AR-depleted CAFs, which promoted the expression of stem cell marker genes in human epithelial PCa cells.

\section{Materials and methods}

\section{Cell culture}

Mouse prostatic stromal cells, NPF and CAF were isolated and established from the $\mathrm{CPten}^{-/-}$prostate cancer mouse model as described previously (Liao et al. 2010a). Briefly, mouse prostatic tissues were minced and cultured in the BFS medium with $1 \mathrm{nM} \mathrm{R} 1881$ (Promega). After 2-4 passages, viable cells growing in a monolayer with flattened, polyhedral morphology consistent with fibroblasts were detectable with microscopy. The passage number of stromal cells used in this work was from 5 to 15 passages. Human prostate cancer cell lines, LNCaP, C4-2B, and PC3 were purchased from ATCC, cultured and maintained in RPMI-1640 with 10\% FBS and 1\% antibiotics. Culture media was replaced every 3 days.

In co-cultures, stromal cells were seeded and cultured in inserts (pore size: $8.0 \mu \mathrm{m}$ ) (BD Bioscience) in 6-well plates with BFS medium. Meanwhile, human PCa cells were seeded in other 6-well plates supplied with RPMI1640 and 10\% FBS. On the second day, inserts with stromal cells were placed above the wells with human PCa cells, and the medium was replaced by fresh RPMI1640 with $0.5 \%$ charcoal-stripped serum (CSS) and either ASOs or enzalutamide (Selleckchem Chemicals) or control treatments as described. Human PCa cells were collected and analyzed after $24 \mathrm{~h}$ or 7 days in co-culture.

\section{Quantitative reverse transcription PCR (RT-qPCR)}

Total cellular RNA, extracted by RNeasy mini kit (Qiagen), was reverse transcribed to cDNA by iScript Reverse Transcription Supermix (Bio-Rad). The reverse transcription reaction was than subjected to PCR amplification using iScript SYBR Green Master (Bio-Rad). PCR signals were recorded and analyzed in CFX96 RealTime PCR Detection System (Bio-Rad) with CFX software (Bio-Rad). RT-qPCR primer sets used in this report are listed in Supplementary Table 1 (see section on supplementary data given at the end of this article). All RT-qPCR results were normalized to either mouse $\beta$-actin for murine genes

Published by Bioscientifica Ltd 
or human GAPDH for human genes and averaged across at least three independent replicates.

\section{Cell proliferation analysis}

Human cells were labeled with GFP and cultured with either mouse NPF or CAF cells in RPMI-1640 (with 5\% CSS and $1 \mathrm{nM} \mathrm{R} 1881$ ) and $2.5 \mu \mathrm{M}$ ASOs. After three days in co-culture, enumeration of GFP-positive cells was performed with flow cytometry.

\section{Two-dimensional (2D) colony-forming assay}

Human PCa cells (500 cells) and mouse CAFs cells $\left(5 \times 10^{4}\right.$ cells) were mixed together and seeded in 6-well dishes with RPMI-1640 and 10\% FBS. Medium was replaced with RPMI-1640 and 0.5\% CSS after $24 \mathrm{~h}$. After 7 days, colonies formed were imaged and counted. Plates were fixed in $4 \%$ PFA and stained by $0.05 \%$ crystal violet. Bright-field images across the entire plate were acquired and colony formation later quantified.

\section{Detection of PSA expression in co-culture}

LNCaP cells $\left(10^{4}\right.$ cells) were seeded with stromal cells ( $10^{4}$ cells) in RPMI-1640 with 10\% FBS in 24-well plates for overnight. On the second day, medium was replaced by fresh RPMI-1640 with $1 \%$ CSS. After $24 \mathrm{~h}$, supernatant was collected and tested for PSA by ELISA (American Qualex).

\section{Cytokine antibody array assay}

Mouse CAFs were seeded in BFS medium supplied with 10\% FBS for overnight. On the second day, cells were further cultured in serum-free BFS medium for $6 \mathrm{~h}$, following by a 24-h culture in BFS with $0.5 \%$ CSS and $2.5 \mu \mathrm{M}$ ASOs. Supernatant was collected and examined in the mouse cytokine antibody array kit panel A (R\&D Systems). Array images were analyzed by HLimage++ software (Machine Vision Tools).

\section{Flow cytometry analysis}

Cultured cells were trypsinized and washed in PBS. After blocking in Cell Staining Buffer (Biolegend) for $10 \mathrm{~min}$ on ice, cells were stained by FITC-conjugated CD44 antibody (eBioscience, $0.1 \mu \mathrm{g} / 10^{6}$ cells) and APC-conjugated CD133 (Miltenyi Biotechnology, $0.1 \mu \mathrm{g} / 10^{6}$ cells) for $20 \mathrm{~min}$ on ice, and then examined using BD LSRII Flow Cytometer with BD FACSDiva and FlowJo software.

\section{Immunohistochemistry (IHC) and immunofluorescent (IF) staining}

Mouse prostatic tissues were dissected from cPten ${ }^{-/}$Luc males. After overnight fixation in 4\% PFA, tissues were processed and sectioned. IHC was performed as previously described with anti-mouse AR antibody (Santa Cruz) at 1:1000 dilution (Liao et al. 2010a). For IF staining, mouse NPF and CAF cells were seeded on Lab Tek II chamber slides (Thermo Scientific) with BFS medium for $24 \mathrm{~h}$, followed by fixing in $4 \%$ PFA for $10 \mathrm{~min}$ and washing with PBS. After blocking, smooth muscle actin (SMA) antibody conjugated with Cy3 dye (Sigma) was applied for $1 \mathrm{~h}$ at a 1:60 dilution. For vimentin (Santa Cruz; 1:50 dilution) and N-Cadherin (Santa Cruz; 1:50 dilution), the primary antibody was applied for $1 \mathrm{~h}$, followed by the staining of secondary antibody conjugated with either FITC or rhodamine. Samples were counter-stained with DAPI and then examined with fluorescent microscopy (Observer.Z1, ZEISS).

\section{Western blot analysis}

Whole-cell lysates were prepared as previously described (Liao et al. 2010a) with anti-mouse AR (1:100; Santa Cruz) and anti-mouse $\beta$-actin (1:1000; Santa Cruz).

\section{Spheroid formation assay}

The basic method was adapted from a previously published protocol (Liao et al. 2010a). Briefly, the CELLection Biotin Binder kit (Invitrogen \#115.33D) was used isolate CD44+ cells using the Indirect Isolation technique with anti-CD44 (eBioscience \#13-0441-82) and anti-human CD16/CD32 and rat IgG2b K isotype as incubation controls (eBioscience 14-0161-82 and 14-4031-82 respectively). One-thousand $\left(10^{3}\right)$ CD44-selected cells were suspended in 2\% Matrigel (BD Bioscience)/RPMI-1640 (1\% FBS) in a total volume of $500 \mu \mathrm{L}$. The mixture was then overlaid into a 24 -well plate pre-coated with $100 \mu \mathrm{L}$ Matrigel. Stromal cells were seeded into an insert (pore size 8.0- $\mu \mathrm{m}$; BD Bioscience) incubated above the well. The mixture was supplied with additional $1.5 \mathrm{~mL}$ RPMI-1640 containing 1\% FBS and ASOs and cultured at $37^{\circ} \mathrm{C}$. Spheroids were stained by $0.05 \%$ crystal violet/PBS and counted at 7 days after plating.

\section{TCGA dataset analysis}

Normalized RNA-seq expression (RSEM) and patient-specific clinical annotations were obtained from the cBio Cancer

Published by Bioscientifica Ltd. 
Genomes portal (http://www.cbioportal.org). The data as reported in (Cancer Genome Atlas 2015) were derived from 236 patients with either low $(n=174)$ or high Gleason $(n=62)$ scores. The unpublished provisional prostate cancer dataset was derived from 491 patients with low $(n=351)$ or high $(n=140)$ Gleason scores. RSEM values corresponding to IFN- $\gamma$ and M-CSF were analyzed using commercially available software (JMP pro, version 12, for Windows). A paired two-tailed $t$ test with a 0.05 confidence interval was used to compare the expression among high Gleason $(9,10)$ or low/intermediate Gleason (6-8) biopsy scores.

\section{Statistical analysis}

All experimental results were repeated a minimum of three times (independent replicates) and are presented as means \pm S.D. Statistical calculations were done with Microsoft Excel analysis tools. Means were compared using a paired Student's $t$ test. A threshold of $P<0.05$ was considered as significant.

\section{Results}

\section{Cancer-associated fibroblasts express low levels of androgen receptor in the $\mathrm{cPten} \mathrm{n}^{-/} \mathrm{L}$ mouse prostate cancer model}

We compared distribution of AR expression in fibroblasts adjacent to normal prostate glands, prostate intraepithelial neoplasia (PIN) and invasive adenocarcinoma in murine prostate tissue (Fig. 1A). In wild-type ( Pten $^{+/+}$ Luc) animals, diffuse positive staining is noted in peri-glandular fibroblasts (indicated by black arrows). Interestingly, $\mathrm{AR}^{+}$fibroblasts are also found adjacent (within $\sim 10 \mu \mathrm{m}$ ) to a PIN lesion in cPten-1-Luc animals. In contrast, more AR- fibroblasts (green arrows) are noted in regions adjacent to invasive cancer (also in cPten ${ }^{-/-L u c}$ animals). This pattern of low AR expression in CAFs is similar to that observed in human PCa patients (Li et al. 2008). We conclude that peri-tumoral stromal cell express low levels of AR relative to PIN or areas of normal prostate in the mouse cPten ${ }^{-/} \mathrm{L}$ model.
A

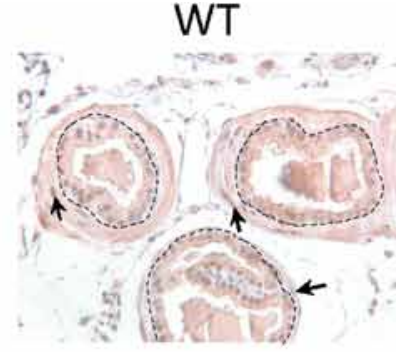

B

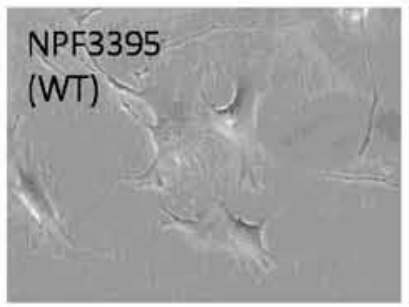

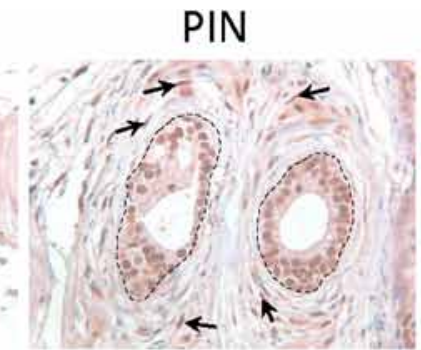

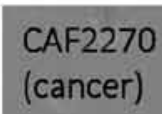

Cancer
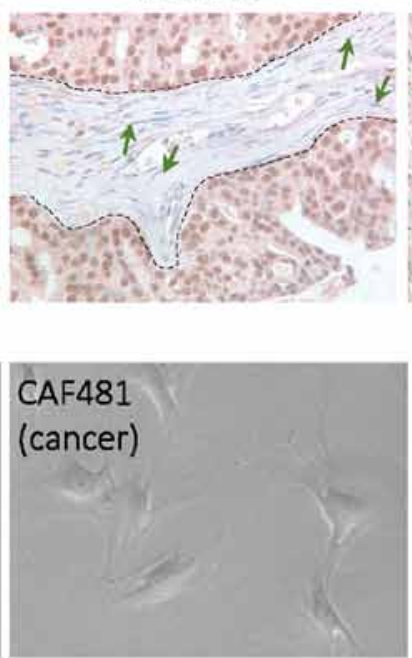

Cancer
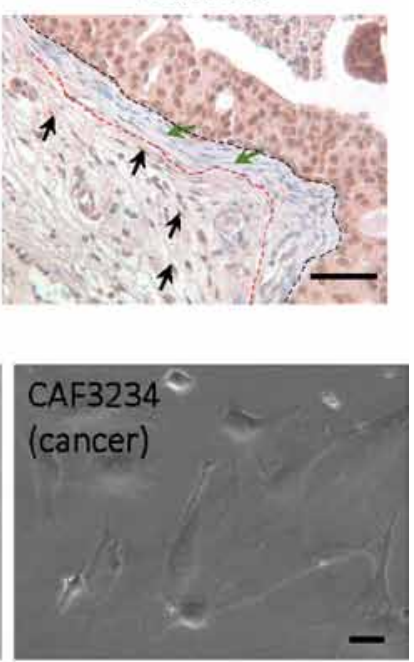

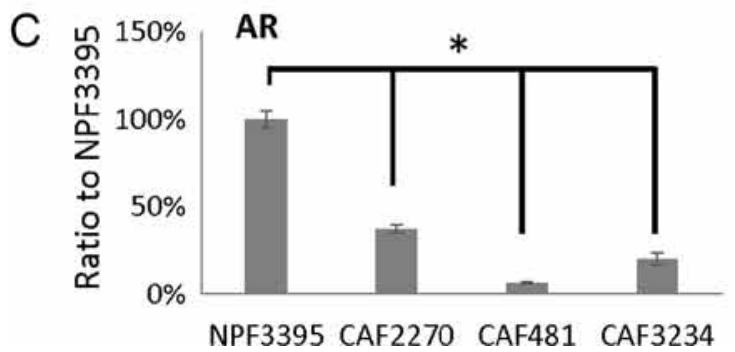

Figure 1

Characterization of mouse prostatic cancer-associated fibroblasts. (A) IHC staining of mouse AR on mouse tissue sections from wildtype, PIN and cancer samples. Black dot line: separating prostate epithelium and stroma; red dot line: separating $A R^{+}$and $A R^{-}$stromal cells; black arrow: $A R^{+}$stromal cell; green arrow: AR- stromal cell. Bar: $10 \mu \mathrm{m}$. (B) Bright field images of mouse NPF and CAF cells. Bar: $10 \mu \mathrm{m}$. (C) Comparison of mouse AR mRNA expressions in mouse NPF and CAF cells by RT-qPCR. This RT-qPCR were repeated at least 3 times. (* $P<0.05)$. 
Stromal cells were isolated from $\mathrm{cPten}^{-/-}$Luc animals for further study. Three mouse CAF cell lines, termed 2270, 3234 and 481, were established from cPten ${ }^{-/}$-Luc animals according to previously published methods (Liao et al. 2010a). A normal prostatic fibroblast (NPF) primary cell line (3395) was also established from a noncancer (cPten ${ }^{+/}$Luc) male mouse as a control. With phase contrast microscopy, both CAFs and NPFs demonstrated an elongated, bipolar morphology typical for fibroblasts (Fig. 1B). All four lines exhibited similar expression levels of SMA, N-Cad and Vimentin expression consistent with a fibroblast phenotype (Supplementary Figs 1 and 2). As expected the CAF lines demonstrated low expression of CK18 expression, a epithelial cell marker, compared to a mouse prostate cancer cell line as previously described (Liao et al. 2010c) (Supplementary Fig. 2). Interestingly, RT-PCR demonstrated AR expression was observed to be 60-90\% lower in CAF lines compared to that in the NPF control (Fig. 1C). Taken together, the CAF2270, CAF3234 and CAF481 cell lines recapitulate the pattern of low AR expression in peri-glandular stromal cells observed in cPten ${ }^{-/}$-Luc prostate cancer.

\section{Mouse AR-ASO specifically knocks down AR expression in mouse cells}

We sought to investigate the functional significance of the low level of AR expression in CAFs using a siRNAbased knockdown strategy. Although siRNA is widely used in transient assays to suppress gene expression in cell culture, the short half-life and instability of siRNA makes this technique difficult to study for longer-term exposures in vitro. Also, siRNA molecules are double-stranded and require lipid-mediated transfection agents to deliver them into cells, which can cause non-specific effects on cells growing in culture and are poorly suited for use as a therapeutic agent in vivo (Frazier 2015). To address these issues, we utilized ASO with 2'-4'-constrained ethyl (cEt)-modifications, which have demonstrated significant pharmacological activities in both preclinical and clinical studies without the need for complex lipid delivery modalities (Hong et al. 2015, Yamamoto et al. 2015).

To test the specificity of the mouse AR-ASO, mouse stromal (CAF2270, CAF234, CAF481 and NPF3395) and human PCa (LNCaP and C4-2B) cells were incubated with various concentrations of the mouse AR-ASO for $24 \mathrm{~h}$ in the absence of any transfection reagent, and cellular RNA extracts were analyzed by RT-PCR. The results show a dose-dependent decrease in mouse AR mRNA levels in the NPF and CAF cell lines compared with treatment with a control ASO with the same chemistry but no known targets in murine cells (Fig. 2A). Additionally, because cells treated with $2.5 \mu \mathrm{M}$ mouse AR-ASO showed a $50 \%$ or greater suppression in mouse AR mRNA expression, this concentration was used for most of the co-culture experiments in this report, unless otherwise specified. The effect of AR-ASO on AR protein expression was confirmed by Western blot as we also observed a significant decrease in $\mathrm{mAR}$ protein expression in NPF and CAF cells after 24-h incubation with $2.5 \mu \mathrm{M}$ mAR-ASO. In contrast,
A
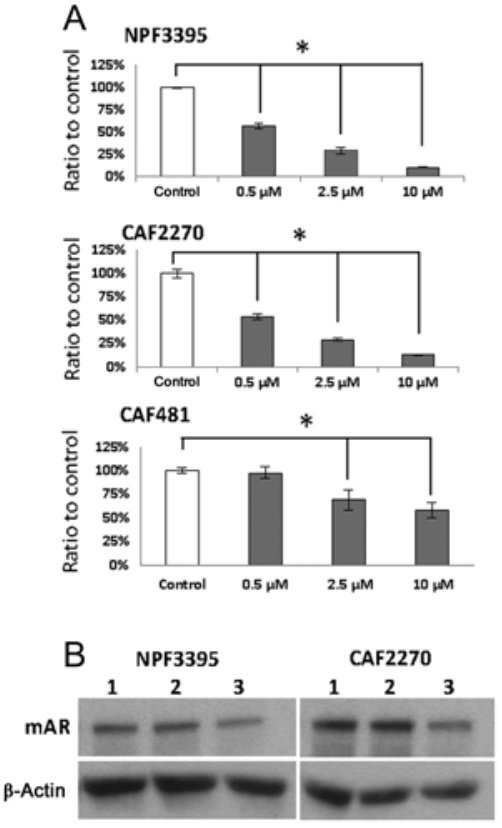
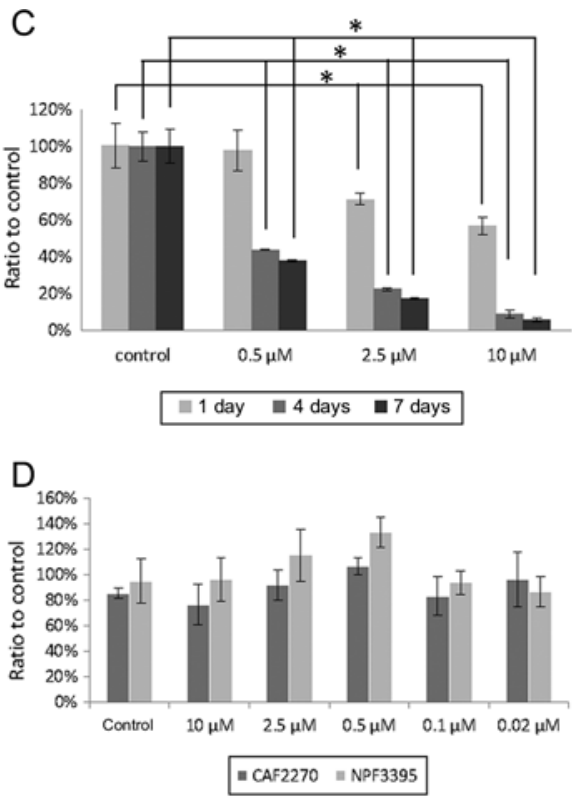

Figure 2

Mouse AR-ASO decreases AR expression in stromal cell lines with little effect on proliferation. (A) RT-PCR results of mouse AR mRNA levels in mouse NPF (3395) and CAF (2270 and 481) cells treated with the mouse AR-ASO for $24 \mathrm{~h}$. (B) Western blot results of mouse AR expression in untreated NPF3395 and CAF2270 (lane 1) or after 24 -h treatment with $2.5 \mu \mathrm{M}$ control ASO (lane 2) or AR-ASO (lane 3). Actin served as the loading control. (C) Mouse CAF3234 cells were treated with mouse AR-ASO at various concentrations for 1, 4 and 7 days. Mouse AR expression was analyzed by RT-qPCR. Control, control-ASO $(10 \mu \mathrm{M}) .\left({ }^{*} P<0.05\right)$. (D) Mouse CAF and NPF cells were treated with $10 \mu \mathrm{M}$ controlASO or mouse AR-ASO at indicated concentrations for $24 \mathrm{~h}$. Proliferation was assessed by MTS assay. Representative results are presented from $\geq 3$ independent replicates. 


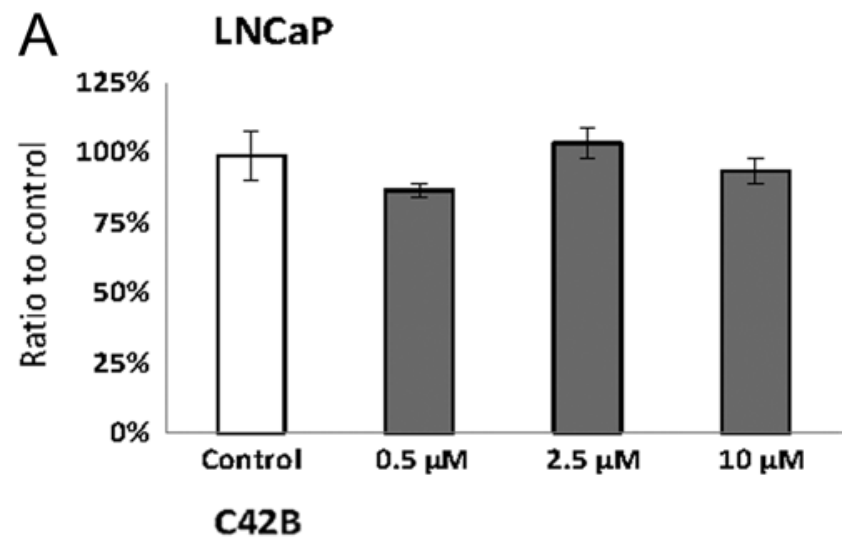

we tested the species specificity of the mAR-ASO. As shown in Fig. 3, we observed no effect after treatment with the mouse AR-ASO on AR expression in the human-dervied, $\mathrm{AR}^{+} \mathrm{LNCaP}$ or $\mathrm{C} 42 \mathrm{~B}$ cell lines. Taken together, our results indicate the mouse AR-ASO is able to specifically target and suppress AR expression without affecting cell growth in mouse prostate stromal cells.

\section{CAF-AR supports prostate cancer cell growth}

To understand the function of stromal $A R$ in prostate cancer, human LNCaP and C4-2B prostate cancer cells were grown along with mouse CAFs. AR expression in CAFs was decreased by treatment with the mouse-specific AR-ASO. Prostate cancer epithelial tumor cells were labeled with GFP by lentiviral vector for enumeration in the co-culture growth assay. In cell proliferation assays, co-culture of LNCaP-GFP or C4-2B-GFP with CAF2270 for 3 days produced a $25 \%$ and $200 \%$ increase in cell proliferation respectively (Fig. 4A and B). The growth-promoting effect of CAFs was attenuated when AR expression was knockeddown in CAF cells by AR-ASO treatment with a $20 \%$ and $65 \%$ decrease in proliferation in LNCaP-GFP and C4-2BGFP co-cultures incubated with AR-ASO respectively.

We next investigated if AR expressed in CAFs influenced the expression of androgen-dependent genes in prostate cancer cells. Using the co-culture approach, we found that CAF2270 increased expression of PSA from LNCaP cells by about 12 -fold after $24 \mathrm{~h}$. However, adding the mouse-specific AR-ASO to the co-culture attenuated PSA expression to only about 6-fold (Fig. 4C). As AR is itself an important AR-target gene (reviewed in Heinlein \& Chang 2004, Brooke \& Bevan 2009, Bluemn \& Nelson 2012), we next investigated the effect of knockdown of AR expression in CAFs on AR expression in cancer cells in the co-culture system. Incubation of LNCaP and C4-2B cells alone with control or the mouse-specific AR-ASO had no effect on cell proliferation or AR expression (Figs 3 and $\mathrm{D}$ and E). However, when LNCaP and C4-2B cells were grown with CAF cells, treatment with AR-ASO led to a decreased AR expression in prostate cancer cells within 1 day (Fig. 4D and E). Taken together, our data show AR expressed in CAFs increases growth and expression of androgen-dependent genes in epithelial cancer cells.

Next, we sought to determine if AR expression in CAFs influenced tumorigenesis using a $2 \mathrm{D}$ colony formation assay. Five hundred LNCaP-GFP cells were seeded with $5 \times 10^{4}$ mouse CAF cells and incubated with control or mAR-ASO. After 7 days, LNCaP-GFP cells formed colonies, which were surrounded by fibroblast cells cell growth after mAR-ASO treatment (Fig. 2D). Finally, 
A

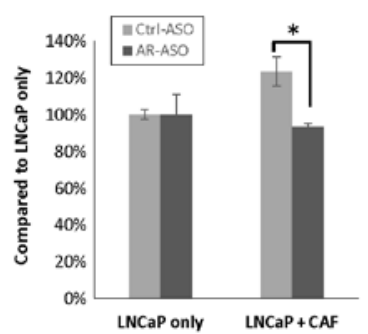

D LNCaP

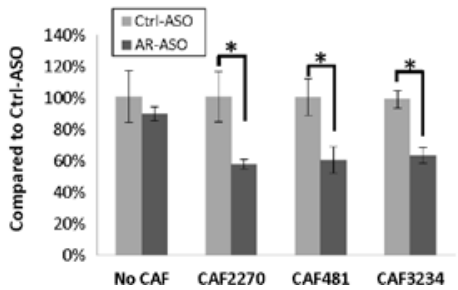

B $\quad$ C4-2B

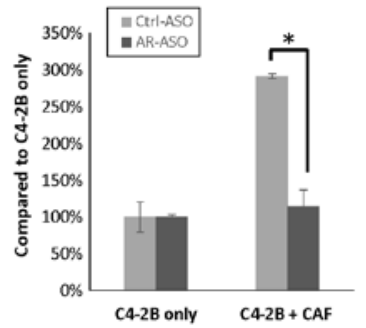

E
C

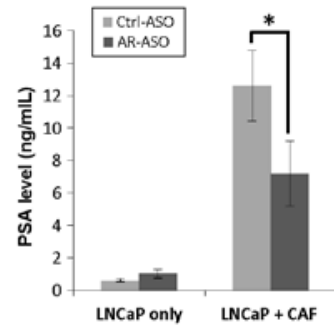

Figure 4

AR expressed in mouse CAFs contributes to the growth of human PCa cells. (A and B) Quantification of GFP-labeled LNCaP (A) and C4-2B (B) cells in co-cultures with CAF2270 assessed by flow cytometer $(n=3)$. C, PSA secretion in media collected after 24 -h co-cultures of LNCaP and mouse CAF2270 assessed by ELISA. ( $D$ and $E$ ) Detection of human $A R$ expression levels in LNCaP (D) and C4-2B (E) 1 day after co-culturing with CAFs and assessed by RT-qPCR $\left({ }^{*} P<0.05\right)$. Representative results are presented from $\geq 3$ independent replicates.
(Fig. 5A). Co-culture of LNCaP cells with CAFs produced 2- to 3-fold more colonies than LNCaP cells cultures alone (Fig. 5B). Knockdown of AR expression in CAF cells significantly reduced LNCaP colony formation, whereas no effect was observed with the control ASO (Fig. 5B and D). A similar effect was observed when AR- PC3 cells were incubated with CAFs in the presence of AR-ASO vs control ASO (Fig. 5C). These results show the importance
A

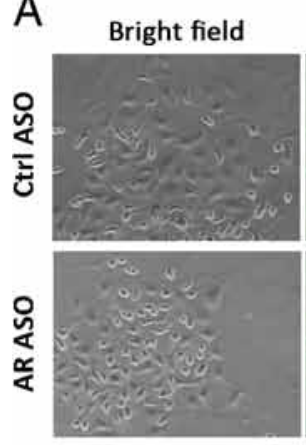

C

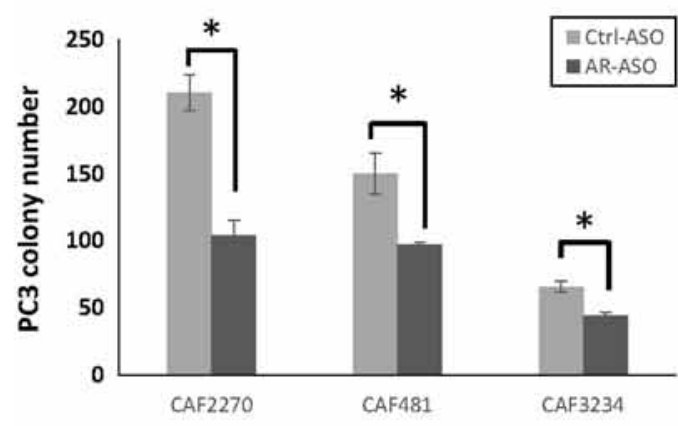

B

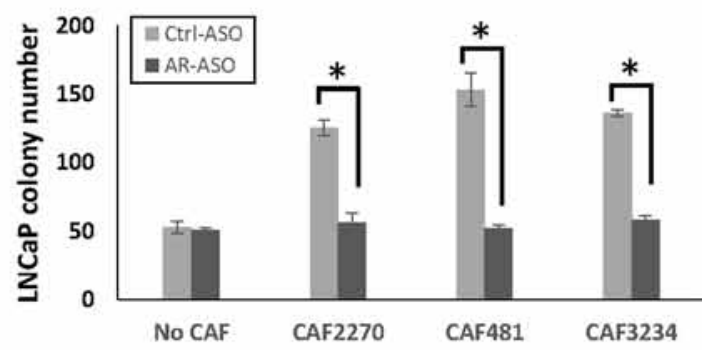

D

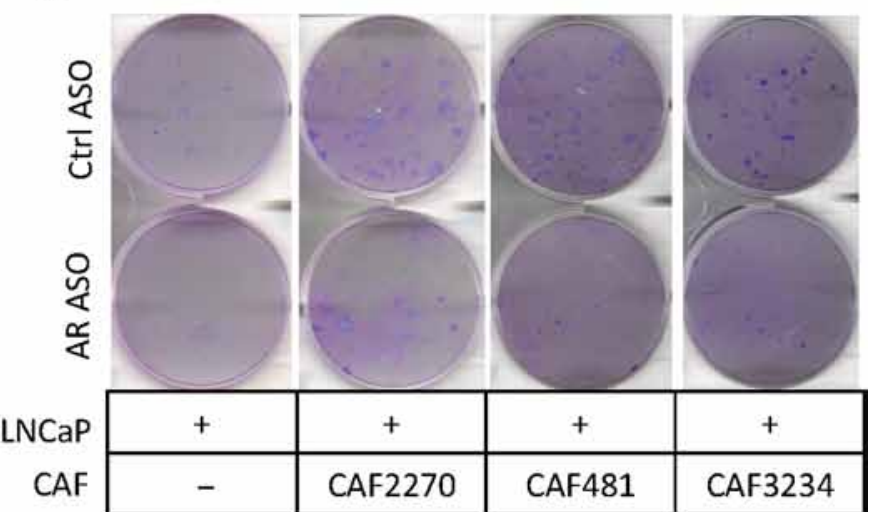

Figure 5

AR expression in CAFs increases colony-forming ability of PCa cells. (A) Cell morphology of LNCaP cells in colonies with CAFs under AR suppression or control. LNCaP cells were labeled with GFP. Bar, $50 \mu \mathrm{m}$. B and C, the comparison of the number of colony formed in LNCaP (B) and PC3 (C) in co-cultures with different CAFs treated with $2.5 \mu \mathrm{M}$ mouse AR-ASO or control ASO (Ctrl-ASO) $(n=3)(* P<0.05)$. (D) Colonies (dark purple) formed from LNCaP in the wells of 6-well plates without or with CAFs on day $7(n=3)$. 
A

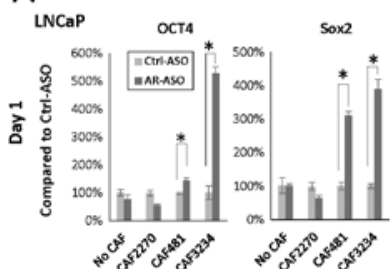

B

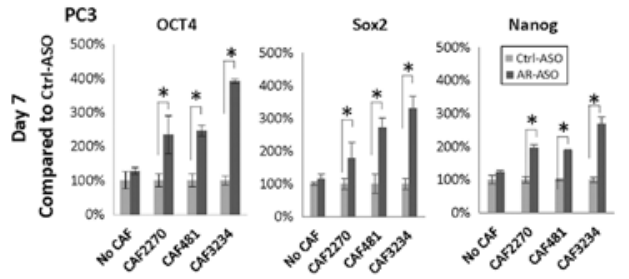

C

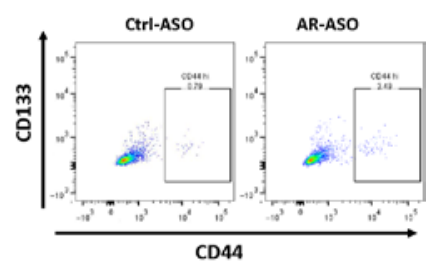

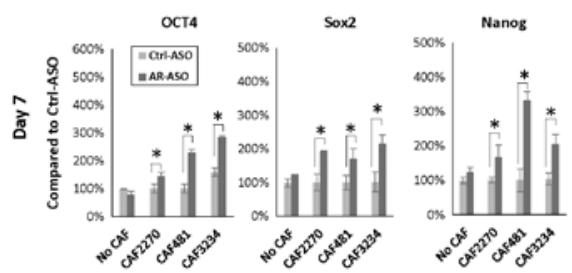

D

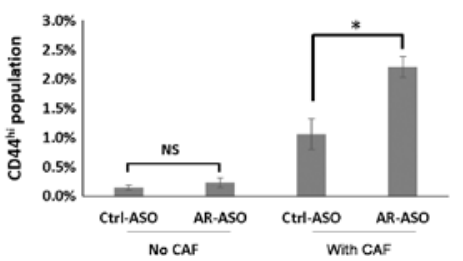

E

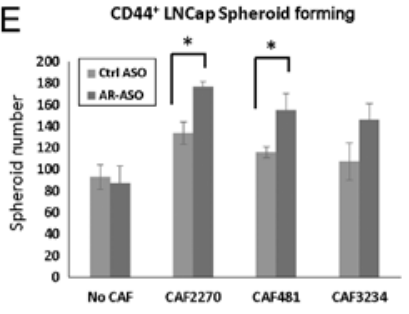

\section{Figure 6}

Decreased AR expression in CAFs increases stem cell marker expression and stem cell population in PCa cells. Expression of Oct4, Sox2 and Nanog in LNCaP (after 1 or 7 days treatment) (A) and PC3 (after 7 days of treatment) (B) cells cultured with or without CAFs after the treatment with $2.5 \mu \mathrm{M}$ AR-ASO or control ASO analyzed with RT-PCR is presented. (C) Flow cytometry analysis of stem cell marker expression in LNCaP cells. 2D gating plot of CD133- and CD44-positive LNCaP cells after 7 days in the presence of CAF3234 and treatment with control-ASO or AR-ASO, as indicated. (D) Relative abundance of CD44hi LNCaP cells in co-cultures with mouse ASOs with or without CAF3234. NS, not significant. (E) Colony formation of CD44+ PCa cells co-cultured with $2.5 \mu \mathrm{M}$ AR-ASO and control ASO, and colonies were counted after 7 days. (* $P<0.05)$. Representative results are presented from $\geq 3$ independent replicates.

of AR expression in CAFs in supporting proliferation and 2D colony formation independent of expression or changes in AR expression in epithelial cells. Overall, we demonstrate that AR expressed in CAFs influences the growth, AR expression and tumorigenic phenotypes in human prostate cancer cells.

\section{AR expression in CAFs influences stem cell marker expression in epithelial cells}

As previous work demonstrated, CAFs can induce stem cell-like characteristics in prostate cancer cells and expression of stem cell markers is known to be related to tumorigenesis (Liao et al. 2010b, Eppert et al. 2011, Merlos-Suarez et al. 2011, Geary et al. 2014, Hu et al. 2016, Syed et al. 2016), we investigated if selective suppression of AR in CAFs affected the expression of stem cell markers in human prostate cancer cells.

RNA was isolated from LNCaP cells grown with CAFs in the presence of AR-ASO or the control ASO and the expression of genes associated with stem cells was analyzed by RT-qPCR. After 1 day, a significant increase in Oct4, Sox 2 and Nanog mRNA levels was noted in most cultures and was observed in all cultures on day 7 (Fig. 6A). We observed a similar trend in co-cultures of PC3 (Fig. 6B) and C4-2B (Supplementary Fig. 3) cells with CAFs.
A

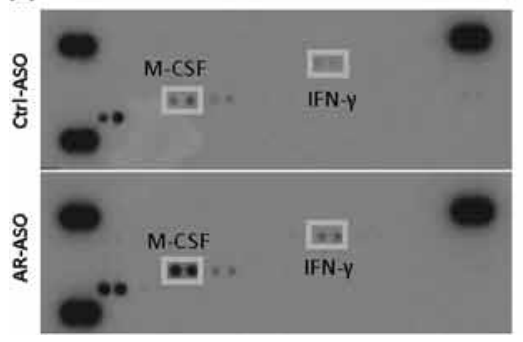

B

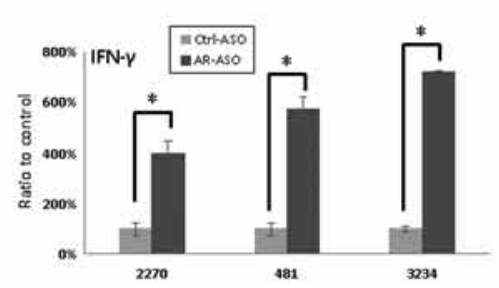

C

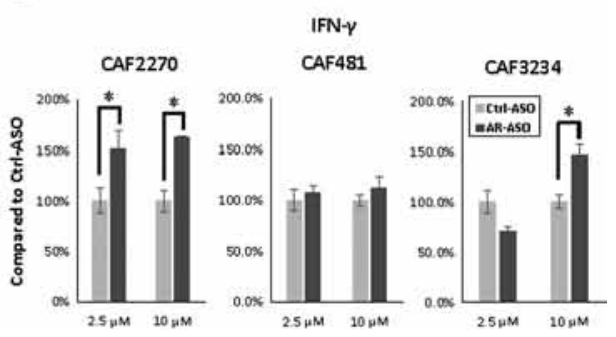

Figure 7

Differential expression of secreted proteins in media obtained from CAF cells incubated with AR-ASO. (A) Representative images of cytokine array incubated with the media from CAF2270 cells treated with AR-ASO or Ctrl-ASO. Tabulated results from multiple independent experiments are presented. Images were quantified and compared across duplicates for IFN- $\gamma$ (B) with media obtained from CAF2270, CAF481 and CAF3234 cells. (C) RT-qPCR detection of IFN-IFN- $\gamma$ in CAFs after treatment with ASOs $(* P<0.05)$. Cytokine array analysis and RT-qPCR were repeated at least 3 times.

http://erc.endocrinology-journals.org DOI: $10.1530 /$ ERC-16-0138
() 2017 Society for Endocrinology Printed in Great Britain
Published by Bioscientifica Ltd 
Our observations suggest that decreasing expression of AR in CAF cells increases the expression of 'stemness' markers in prostate cancer cells.

Next, we sought to validate the relationship between $\mathrm{AR}$ expression in CAF and stem cell marker expression in prostate cancer cells at the protein level. CD133 and CD44 are considered markers for cancer stem cells based on their enrichment in cells with 'stem cell-like' properties such as tumor initiation and treatment resistance (Collins et al. 2005, Clevers 2011). Therefore, we tested whether inhibition of AR expression in CAFs influenced the expression of CD133 and CD44 in prostate cancer cells (Fig. 6C and D). No significant CD133 expression was detected in LNCaP cells in any of the conditions tested. However, CD44+ was detected in a small sub-population $(\sim 0.2 \%)$ of LNCaP cells. Co-culture of the LNCaP cells with CAF3234 significantly increased the proportion of CD 44 hi cells to $1 \%$, which was even further increased to $2.2 \%$ by treatment with AR-ASO
(Fig. 6C and D). Thus, our results show that co-culture with AR-depleted CAFs leads to significantly increased expression of stem cell markers in human PCa cells.

Our previous study revealed that the spheroidforming ability of PCa CSCs in 3D cultures is highly regulated by CAFs (Liao et al. 2010a). Therefore, to investigate whether stromal AR in CAF may participate in this regulation, we performed spheroid-forming assay by co-culturing CD44+-enriched LNCaP cells with CAFs and ASOs in Matrigel. Although spheroid formation was observed in all conditions, incubation with AR-depleted CAFs significantly increased LNCaP spheroid formation compared to controls (Fig. 6E). However, no effect was observed when AR-depleted CAFs were incubated with unsorted LNCaP cells (data not shown). These results suggest that AR-depleted CAFs promote the growth of a sub-population of epithelial cancer cells with stem celllike features.

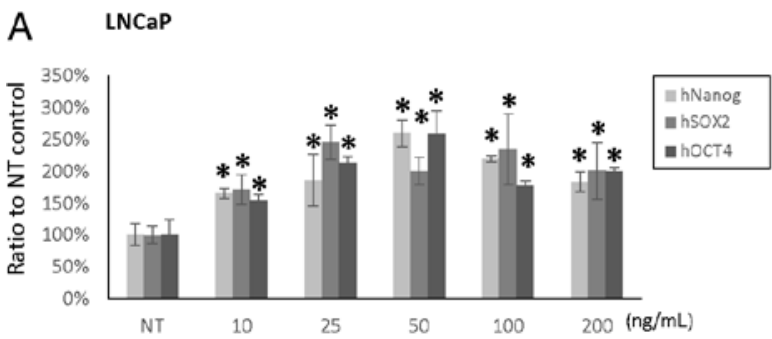

B
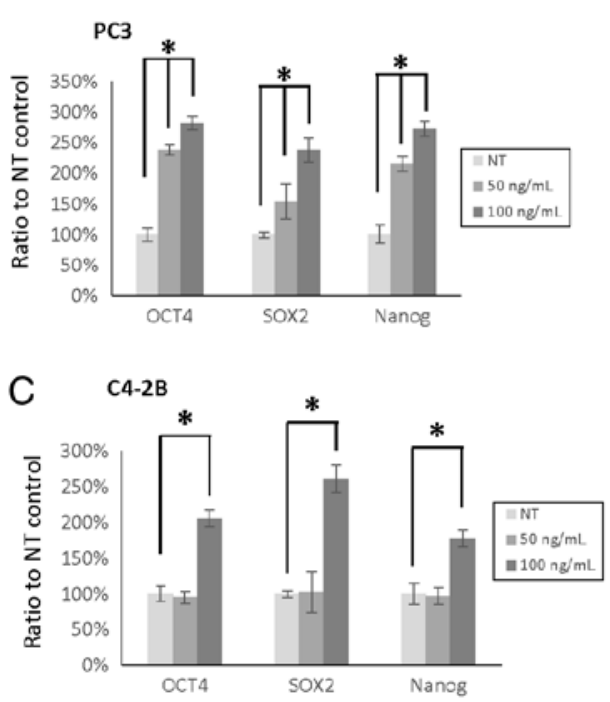

$\mathrm{D}$

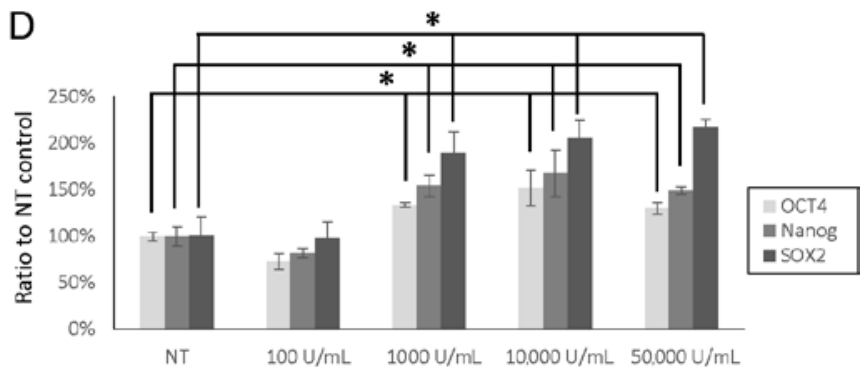

$\mathrm{E}$

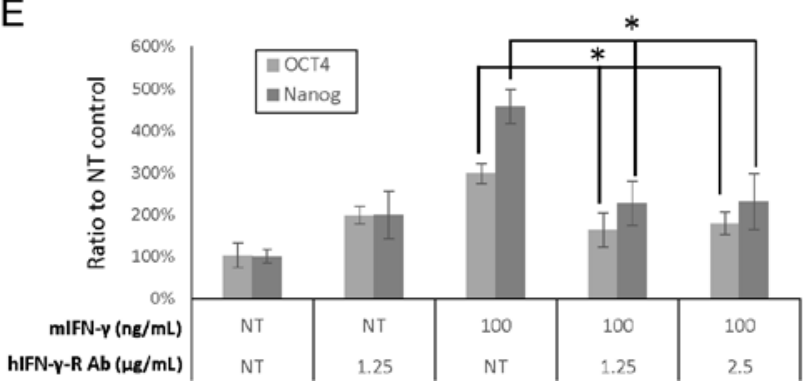

\section{Figure 8}

IFN- $\gamma$ stimulates the expression of 'stemness' markers in PCa cells, which is attenuated by anti-IFN- $\gamma \mathrm{R}$ antibody. LNCaP (A), PC3 (B) and C4-2B (C) cells were treated with mIFN- $\gamma$ treatment for $24 \mathrm{~h}$ at the doses indicated. (D) LNCaP cells were treated with hIFN- $\gamma$ at the indicated doses for $24 \mathrm{~h}$. (E) LNCaP cells incubated with mIFN- $\gamma$ and anti-IFN- $\gamma$ R antibody for $24 \mathrm{~h}$ at the doses indicated. NT, non-treated. (*P<0.05). Representative results are presented from $\geq 3$ independent replicates. 
A
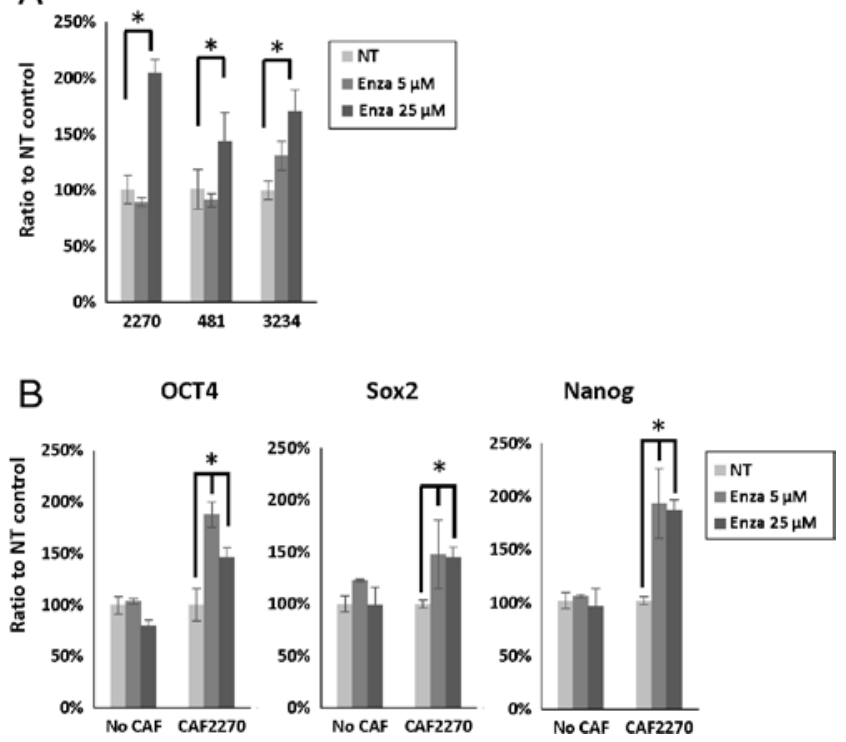

Figure 9

Enzalutamide increases IFN- $\gamma$ and stem cell marker expression in CAFs and prostate cancer cells. (A) RT-qPCR results of IFN- $\gamma$ expression in CAFs treated with 5 or $25 \mu \mathrm{M}$ enzalutamide or no treatment (NT) control. (B) RT-qPCR results of Oct4, Sox2 and Nanog expression PC3 cells co-cultured with CAFs and treated 5 or $25 \mu \mathrm{M}$ enzalutamide for $24 \mathrm{~h}, * P<0.05$. Representative results are presented from $\geq 3$ independent replicates.

\section{IFN- $\gamma$ and M-CSF are AR-regulated factors secreted by} CAFs, which affect stem cell marker expression in PCa cells

As the changes in stem cell marker expression were observed with CAFs grown on porous inserts placed above prostate cancer cells, we hypothesized that soluble factors produced by CAFs could mediate this effect. We used a commercially available antibody array to investigate differential expression of secreted proteins in CAF-conditioned media after culture with AR-ASO or control ASO. Mouse CAFs were seeded in RPMI-1640 with $10 \%$ FBS overnight. Then, the media was changed to $0.5 \%$ CSS for $6 \mathrm{~h}$ followed by treatment with AR-ASO or control ASO. The cell-free supernatants were collected and protein expression in the conditioned media was analyzed with a commercially available cytokine antibody array (Fig. 7A). With this approach, we identified IFN- $\gamma$ and M-CSF as candidate cytokines upregulated in AR-ASOtreated CAF2270. Similar results were observed with the other CAF cell lines such that treatment with mAR-ASO led to $\sim 4$ - to 6-fold induction of IFN- $\gamma$ (Fig. 7B) and $\sim 1$ to 3-fold induction of M-CSF (Supplementary Fig. 4). We used RT-qPCR to confirm the results observed with the protein array. Specifically, we observed an increased in IFN- $\gamma$ expression in CAFs after treatment with the AR-ASO
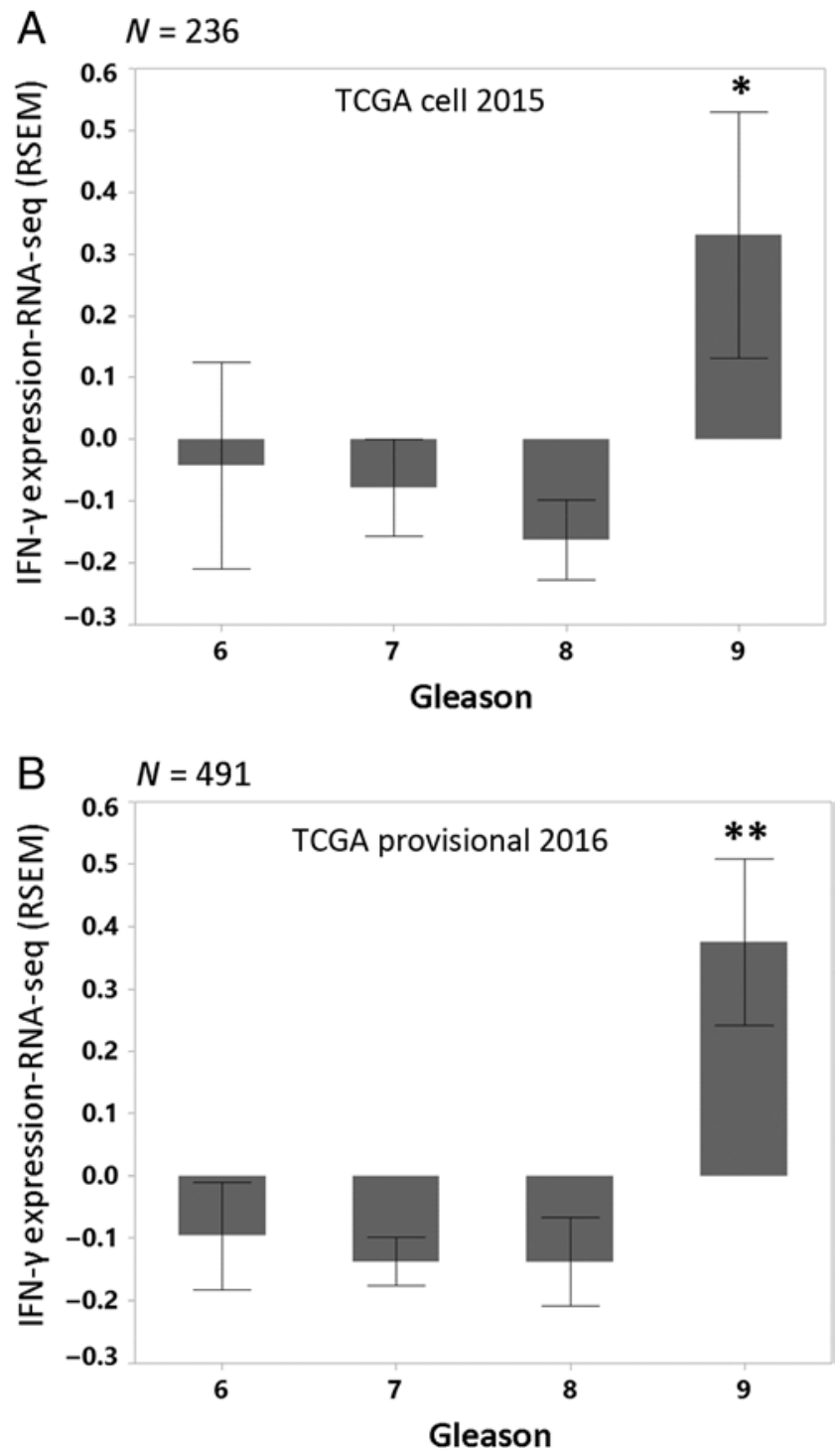

Figure 10

Patients with Gleason score 9 and above showed elevated IFN- $\gamma$ expression. Two TCGA datasets with clinical annotation including Gleason scores were used to interrogate the RNA expression of IFN- $\gamma$ : (A) 236 patients from the dataset published in Cell $(2015)\left({ }^{*} P<0.006\right)$ and $(B) 491$ patients from unpublished provisional prostate cancer dataset (Cerami et al. 2012, Gao et al. 2013) (**P<0.0001).

(Fig. 7D). Therefore, we hypothesized that IFN- $\gamma$ and M-CSF could promote expression of stem cell genes in prostate cancer cells.

To further explore the effects of IFN- $\gamma$ on human prostate cancer cells, LNCaP cells were treated with increasing doses of mouse IFN- $\gamma(\mathrm{mIFN}-\gamma, 10-200 \mathrm{ng} / \mathrm{mL}$ ) or a vehicle control and the expression of Nanog, Sox 2 and Oct4 were measured by RT-qPCR. The results show a dosedependent increase in expression of all 3 stem cell markers after mIFN- $\gamma$ treatment in LNCaP, PC3 and C4-2B cells (Fig. 8A, B and C). Similar results were observed for human

Published by Bioscientifica Ltd. 
IFN- $\gamma$ (hIFN- $\gamma$ ) treatment. Specifically, we also observed a dose-dependent increase in Oct4, Nanog and Sox2 with hIFN- $\gamma$ treatment of LNCaP cells (Fig. 8D). Finally, the effect of mIFN- $\gamma$ on stem cell marker expression was confirmed using a blocking antibody. Specifically, LNCaP cells were treated with mIFN- $\gamma$ with or without an IFN- $\gamma$ receptor blocking antibody (anti-hIFN- $\gamma \mathrm{R}$ ). The results show that anti-hIFN- $\gamma \mathrm{R}$ decreases the stimulation of Oct4 and Nanog observed with mIFN- $\gamma$ treatment of CAF cells.

A similar approach was used to explore the effects of M-CSF on stem cell marker expression in human prostate cancer cells. Accordingly, mouse M-CSF (mM-CSF) demonstrated a dose-dependent increase in stem cell marker expression in LNCaP, PC3 and C4-2B cells (Supplementary Fig. 5A, B and C). A similar dose-dependent effect on Oct4, Sox 2 and Nanog expression was also observed in LNCaP cells treated with human M-CSF (Supplementary Fig. 5D). Furthermore, M-CSF-receptor blocking antibody decreased the effect of mM-CSF treatment on Oct4 and Nanog expression (Supplementary Fig. 5E).

\section{Anti-androgen treatment promotes the expression of IFN- $\gamma$ and stem cell markers}

Enzalutamide is a highly potent anti-androgen recently approved for the treatment of metastatic castrate-resistant prostate cancer. As anti-androgen treatments are expected to exert effects equally on stromal and epithelial cells, we sought to confirm the results observed with the AR-depleted CAFs with enzalutamide treatment in the same co-culture system. First, we observed the treatment of CAF cells with $25 \mu \mathrm{M}$ enzalutamide for increased IFN- $\gamma$ expression analyzed with RT-qPCR (Fig. 9A). As PC3 represents an AR- human prostate cancer cell line, enzalutamide has no effect on the growth of this cell line. In control cultures without CAFs, enzalutamide did not affect the mRNA expressions of Oct4, Sox 2 and Nanog in PC3 after 24h (Fig. 9B). However, when CAFs were grown along with PC3 cells, enzalutamide significantly increased stem cell marker expression (Fig. 9B). Thus, these results support the importance of stromal AR signaling on promoting stem cell expression in prostate cancer cells.

\section{Elevated IFN- $\gamma$ expression is associated with high Gleason grade}

Pathologic Gleason grade is a critical pathologic feature used in prognostication and treatment planning for patients with newly diagnosed prostate cancer (Epstein et al. 2006). Our data suggest that IFN- $\gamma$ expression in prostate tissue would promote the growth of a rare subpopulation of epithelial cancer cells with stem cell-like phenotypes. Other data suggest that increases in a stem cell-like population would be expected to lead to worse prognosis. Thus, we investigated a possible link between IFN- $\gamma$ and Gleason score. We identified two TCGA datasets (Cerami et al. 2012, Gao et al. 2013) with patient-specific annotations including Gleason score and gene expression. Interrogation of these TCGA datasets revealed that INF- $\gamma$ expression is elevated in patients with high Gleason score $(P<0.006$ and $<0.0001$, Fig. 10A and B).

\section{Discussion}

In this report, we explored the role of AR expressed in CAFs to the growth and development of prostate cancer. Our work suggests that although AR is decreased in fibroblasts isolated from areas near malignant glands compared with those isolated from non-malignant regions, this residual AR is still functional. Specifically, we show AR expressed in CAFs contributes to the tumor-promoting abilities that CAFs exert on epithelial prostate cancer cells. Further, we found that decreased AR expression in CAFs is also associated with an increase in stem cell marker gene expression in prostate cancer epithelial cells. Finally, we identify IFN- $\gamma$ and M-CSF as candidate cytokines secreted by CAFs and increased by AR suppression, which promote the expression of stem cell markers in prostate cancer cells.

IFN- $\gamma$ has been extensively studied based on its potent role as an immunomodulatory cytokine relevant to immune response and cancer (Borden et al. 2007). Of particular relevance, IFN- $\gamma$ has been associated with both pro- and anti-tumor effects depending on factors specific tumor types, microenvironments and immune contexts (Zaidi \& Merlino 2011). Although stem cell markers are not known to be direct IFN- $\gamma$-regulated genes, IFN- $\gamma$ has been associated with changes in development and differentiation in the hematopoietic and lymphocytic systems (Schroder et al. 2004, Baldridge et al. 2010, de Bruin et al. 2013). Similarly, increased IFN- $\gamma$ signaling has been associated with aplastic anemia in patients (Dufour et al. 2004, Chang et al. 2010, Serio et al. 2011, Lin et al. 2014) and with induction of a hematopoietic stem cell phenotype in an animal model (Lin et al. 2014). However, we are not aware of any previous studies, which suggested a role of IFN- $\gamma$ in epithelial cell reprogramming or maintenance of cancer stem cells.

M-CSF (also known as colony-stimulating-factor-1, CSF1) has also been previously studied in the context of

Published by Bioscientifica Ltd 
immune regulation and cancer (Stanley et al. 1997). M-CSF controls survival and differentiation of macrophages. Mice homozygous for an inactivating M-CSF mutation exhibit osteopetrosis due to a defect in generation of osteoclasts, a specialized type of tissue macrophage (Yoshida et al. 1990). High M-CSF expression has been associated with early development of metastasis and a poor prognosis for a variety of solid tumors including breast, ovarian, endometrial, sarcoma and renal cell carcinoma (Laoui et al. 2014). M-CSF/CSF1R signaling is involved in recruitment of tumor-associated macrophages. In particular, M-CSF/ CSF1R promotes differentiations and survival of TAMs with an M2-like, 'pro-tumorigenic' phenotype. Recently, Escamilla and coworkers reported on the role of M-CSF/ CSF1R and androgen-deprivation therapy in prostate cancer. Specifically, they found that androgen-deprivation therapy induced recruitment of TAMs, which expressed CSF1R and exhibited an M2-phenotype. Anti-androgen therapy increased M-CSF expression in cancer cells and a CSF1R inhibitor increased the duration of response to androgen-blocking therapy. The current work shows that CAFs are also a potent source of M-CSF in response to androgen-targeting therapy, which can also support the recruitment of M2 TAMs and may be therapeutically targeted with M-CSF/CSF1R inhibitors, which could lead to the improvement in the efficacy and durability of ADT for prostate cancer.

Other data suggest that acquisition of stem cell marker expression and stem cell phenotypes are critical in primary prostate cancer tumorigenesis and progression to treatment-resistant, metastatic prostate cancer (Glinsky et al. 2005, Goldstein et al. 2010, Markert et al. 2011, Smith et al. 2015). Based on the CSC hypothesis, cancer cells can be characterized into three groups: CSCs, transient-amplifying (TA) cells, terminal-differentiation (TD) cells and only CSCs are immortalized with no limitation in proliferation and are able to be resistant to cancer treatments (Pfeiffer \& Schalken 2010). Here, we show that decreasing expression of AR in CAFs can stimulate stem cell marker expression in PCa cells, though it is unclear, which cell sub-population (CSC, TA or TD) is affected by the signals. Moreover, although both IFN- $\gamma$ and M-CSF are identified as stromally secreted factors that influence stem cell marker expression, our work does not exclude the presence of other factors, which could work alone or together along with IFN- $\gamma$ and M-CSF to promote cancer stem cell marker expression.

Interestingly, we found AR-depleted CAFs supported cancer epithelial cells to form spheroids in matrigel in 3D cultures, but not colonies in a $2 \mathrm{D}$ proliferation assay. It has been reported that cancer spheroids in biomaterial scaffolds are developed from single CSCs, which differentiate to various daughter cells that construct glandular-like spheroids in three-dimensional environment (Leong et al. 2008, Liao et al. 2010a). Similar to normal stem cells, the role of CSCs in cancer is majorly maintaining the homeostasis of cancer (Lawson \& Witte 2007). And the growth of cancer is contributed by proliferation of more differentiated cancer cells (White \& Lowry 2015). Hence, the secreted signaling by AR-depleted CAFs is most likely directing the fate of CSCs, not differentiated cells, in prostate cancer development.

Our results should be viewed in context with other reports also focusing on the role of stromal AR expression in prostate cancer. Previously, Tanner and coworkers found that genes in the TGF $\beta$, Wnt, Hedgehog and MAP kinase pathways were differentially expressed in androgen-treated, AR-transfected human prostate stromal cell line (WPMY) (Tanner et al. 2011). Subsequently, Leach and coworkers found that stromal AR is important in the maintenance of an extracellular matrix, which is less permissive to prostate cancer cell invasion using AR-transfected, hTERT-immortalized prostate myofibroblast cell lines in a subrenal capsule tumor formation model (Leach et al. 2015). Neither of these studies report changes in IFN- $\gamma$ or M-CSF expression after AR transfection or androgen stimulation. This may reflect the inherent limitations in the techniques and cell lines used for these studies as our approach focused on changes in secreted proteins associated with decreased AR expression. Thus, we provide the first evidence that stromal AR and epithelial stemness are linked through the IFN- $\gamma$ and M-CSF regulation pathways.

A unique feature of our approach is the use of murinehuman co-culture system, which allows for the speciesspecific knockdown of mAR in CAF cells without direct effects on AR expression in epithelial cancer cells (Figs 2 and 3). Xenografts are a standard approach to study human prostate cancer cells in the context of murine stromal tissues in vivo. Here, we have extended this methodology by mixing murine stromal cells with human prostate cancer epithelial cells with a co-culture system in vitro. However, there are potential limitations inherent in our approach as it is possible that there are speciesspecific differences in signaling pathways and cellular responses, which could limit the generalizability of our observations to human cancer patients. Although we did verify the effects of both human and murine-derived IFN- $\gamma$ and M-CSF on prostate cancer cells, we cannot rule out the possibility of the AR expression in human stromal

Published by Bioscientifica Ltd 
cells react differently to AR depletion than our studies based on murine CAFs.

The clinical relevance of our work extends to the use of androgen-deprivation therapy in caring for patients with advanced prostate cancer. While targeting the androgen axis in epithelial cancer cells has been the focus for drug development in caring for prostate cancer patients, our work suggests that efforts should also be directed at understanding the relative effects on androgen targeting and other therapies on the stromal compartment as well. Further, one could envision a strategy of combining stromal- and epithelial-targeting therapies to produce maximize an anti-cancer effect. Additional studies will be needed to more directly translate these results into patient care.

\section{Supplementary data}

This is linked to the online version of the paper at http://dx.doi.org/10.1530/ ERC-16-0138.

\section{Declaration of interest}

A Robert MacLeod/Youngsoo Kim: Employment, Stock Ownership, Patents/Intellectual Property with Ionis Pharmaceuticals.

\section{Funding}

The authors would like to express our deepest gratitude to our philanthropic supporters, Gladys and Melvin Rubin, whose generous support made this research possible. This work was partially supported by National Cancer Institute Cancer Center Shared Grant award P30CA014089.

\section{Acknowledgements}

The authors thank Dr David Agus and all members of the Center for Applied Molecular Medicine for assistance in various aspects of this work. They also gratefully acknowledge Dr Pradip Roy-Burman for providing mouse prostatic stromal cells. The content is solely the responsibility of the authors and does not necessarily represent the official views of the National Cancer Institute or the National Institutes of Health.

\section{References}

Baldridge MT, King KY, Boles NC, Weksberg DC \& Goodell MA 2010 Quiescent haematopoietic stem cells are activated by IFN-gamma in response to chronic infection. Nature 465 793-797. (doi:10.1038/ nature09135)

Bluemn EG \& Nelson PS 2012 The androgen/androgen receptor axis in prostate cancer. Current Opinion in Oncology 24 251-257. (doi:10.1097/CCO.0b013e32835105b3)

Borden EC, Sen GC, Uze G, Silverman RH, Ransohoff RM, Foster GR \& Stark GR 2007 Interferons at age 50: past, current and future impact on biomedicine. Nature Reviews Drug Discovery 6 975-990. (doi:10.1038/nrd2422)

Brooke GN \& Bevan CL 2009 The role of androgen receptor mutations in prostate cancer progression. Current Genomics 10 18-25. (doi:10.2174/138920209787581307)
Cancer Genome Atlas Research Network 2015 The molecular taxonomy of primary prostate cancer. Cell 163 1011-1025. (doi:10.1016/j. cell.2015.10.025)

Cerami E, Gao J, Dogrusoz U, Gross BE, Sumer SO, Aksoy BA, Jacobsen A, Byrne CJ, Heuer ML, Larsson E, et al. 2012 The cBio cancer genomics portal: an open platform for exploring multidimensional cancer genomics data. Cancer Discovery 2 401-404. (doi:10.1158/2159-8290.CD-12-0095)

Chang H, Zeng F, Zhang JY, Mu XY, Meng WT, Ma HB \& Liu T 2010 Association of the interferon-gamma single nucleotide polymorphism +874 (T/A) with response to immunosuppressive therapy in patients with severe aplastic anemia. Blood Cells, Molecules, and Diseases $\mathbf{4 5}$ 313-316. (doi:10.1016/j.bcmd.2010.09.003)

Clevers H 2011 The cancer stem cell: premises, promises and challenges. Nature Medicine 17 313-319. (doi:10.1038/nm.2304)

Collins AT, Berry PA, Hyde C, Stower MJ \& Maitland NJ 2005 Prospective identification of tumorigenic prostate cancer stem cells. Cancer Research 65 10946-10951. (doi:10.1158/0008-5472.CAN-052018)

Cunha GR, Ricke W, Thomson A, Marker PC, Risbridger G, Hayward SW, Wang YZ, Donjacour AA \& Kurita T 2004 Hormonal, cellular, and molecular regulation of normal and neoplastic prostatic development. Journal of Steroid Biochemistry and Molecular Biology 92 221-236. (doi:10.1016/j.jsbmb.2004.10.017)

de Bruin AM, Demirel O, Hooibrink B, Brandts CH \& Nolte MA 2013 Interferon-gamma impairs proliferation of hematopoietic stem cells in mice. Blood 121 3578-3585. (doi:10.1182/blood-2012-05432906)

Dufour C, Capasso M, Svahn J, Marrone A, Haupt R, Bacigalupo A, Giordani L, Longoni D, Pillon M, Pistorio A et al. 2004 Homozygosis for (12) CA repeats in the first intron of the human IFN-gamma gene is significantly associated with the risk of aplastic anaemia in Caucasian population. British Journal of Haematology 126 682-685. (doi:10.1111/j.1365-2141.2004.05102.x)

Eppert K, Takenaka K, Lechman ER, Waldron L, Nilsson B, van Galen P, Metzeler KH, Poeppl A, Ling V, Beyene J, et al. 2011 Stem cell gene expression programs influence clinical outcome in human leukemia. Nature Medicine 17 1086-1093. (doi:10.1038/nm.2415)

Epstein JI, Allsbrook WC Jr, Amin MB \& Egevad LL 2006 Update on the Gleason grading system for prostate cancer: results of an international consensus conference of urologic pathologists. Advances in Anatomic Pathology 13 57-59. (doi.org/10.1097/01. pap.0000202017.78917.18)

Frazier KS 2015 Antisense oligonucleotide therapies: the promise and the challenges from a toxicologic pathologist's perspective. Toxicologic Pathology 43 78-89. (doi:10.1177/0192623314551840)

Gao J, Aksoy BA, Dogrusoz U, Dresdner G, Gross B, Sumer SO, Sun Y, Jacobsen A, Sinha R, Larsson E, et al. 2013 Integrative analysis of complex cancer genomics and clinical profiles using the cBioPortal. Science Signaling 6 pl1. (doi.org/10.1126/scisignal.2004088)

Geary LA, Nash KA, Adisetiyo H, Liang M, Liao CP, Jeong JH, Zandi E \& Roy-Burman P 2014 CAF-secreted annexin A1 induces prostate cancer cells to gain stem cell-like features. Molecular Cancer Research 12 607-621. (doi:10.1158/1541-7786.MCR-13-0469)

Glinsky GV, Berezovska O \& Glinskii AB 2005 Microarray analysis identifies a death-from-cancer signature predicting therapy failure in patients with multiple types of cancer. Journal of Clinical Investigation 115 1503-1521. (doi:10.1172/JCI23412)

Goldstein AS, Huang J, Guo C, Garraway IP \& Witte ON 2010 Identification of a cell of origin for human prostate cancer. Science 329 568-571. (doi:10.1126/science.1189992)

Heinlein CA \& Chang C 2004 Androgen receptor in prostate cancer. Endocrine Reviews 25 276-308. (doi:10.1210/er.2002-0032)

Henshall SM, Quinn DI, Lee CS, Head DR, Golovsky D, Brenner PC, Delprado W, Stricker PD, Grygiel JJ \& Sutherland RL 2001 Altered expression of androgen receptor in the malignant epithelium and

Published by Bioscientifica Ltd. 
adjacent stroma is associated with early relapse in prostate cancer. Cancer Research 61 423-427.

Hong D, Kurzrock R, Kim Y, Woessner R, Younes A, Nemunaitis J, Fowler N, Zhou T, Schmidt J, Jo M, et al. 2015 AZD9150, a nextgeneration antisense oligonucleotide inhibitor of STAT3 with early evidence of clinical activity in lymphoma and lung cancer. Science Translational Medicine 7 314ra185. (doi:10.1126/scitranslmed. aac5272)

Hu QP, Kuang JY, Yang QK, Bian XW \& Yu SC 2016 Beyond a tumor suppressor: soluble E-cadherin promotes the progression of cancer. International Journal of Cancer 138 2804-2812. (doi:10.1002/ijc.29982)

Huggins C \& Hodges CV 1972 Studies on prostatic cancer. I. The effect of castration, of estrogen and androgen injection on serum phosphatases in metastatic carcinoma of the prostate. CA: A Cancer Journal for Clinicians 22 232-240. (doi:10.3322/canjclin.22.4.232)

Kurita T, Wang YZ, Donjacour AA, Zhao C, Lydon JP, O'Malley BW, Isaacs JT, Dahiya R \& Cunha GR 2001 Paracrine regulation of apoptosis by steroid hormones in the male and female reproductive system. Cell Death and Differentiation 8 192-200. (doi:10.1038/sj.cdd.4400797)

Lai KP, Yamashita S, Huang CK, Yeh S \& Chang C 2012 Loss of stromal androgen receptor leads to suppressed prostate tumourigenesis via modulation of pro-inflammatory cytokines/chemokines. EMBO Molecular Medicine 4 791-807. (doi:10.1002/emmm.201101140)

Laoui D, Van Overmeire E, De Baetselier P, Van Ginderachter JA \& Raes G 2014 Functional relationship between tumor-associated macrophages and macrophage colony-stimulating factor as contributors to cancer progression. Frontiers in Immunology 5489. (doi:10.3389/fimmu.2014.00489)

Lawson DA \& Witte ON 2007 Stem cells in prostate cancer initiation and progression. Journal of Clinical Investigation 117 2044-2050. (doi:10.1172/JCI32810)

Leach DA, Need EF, Toivanen R, Trotta AP, Palethorpe HM, Tamblyn DJ, Kopsaftis T, England GM, Smith E, Drew PA, et al. 2015 Stromal androgen receptor regulates the composition of the microenvironment to influence prostate cancer outcome. Oncotarget 6 16135-16150. (doi:10.18632/oncotarget.3873)

Leong KG, Wang BE, Johnson L \& Gao WQ 2008 Generation of a prostate from a single adult stem cell. Nature $\mathbf{4 5 6} 804-808$. (doi:10.1038/nature07427)

Li Y, Li CX, Ye H, Chen F, Melamed J, Peng Y, Liu J, Wang Z, Tsou HC, Wei J, et al. 2008 Decrease in stromal androgen receptor associates with androgen-independent disease and promotes prostate cancer cell proliferation and invasion. Journal of Cellular and Molecular Medicine 12 2790-2798. (doi:10.1111/j.1582-4934.2008.00279.x)

Liao CP, Adisetiyo H, Liang M \& Roy-Burman P 2010a Cancer-associated fibroblasts enhance the gland-forming capability of prostate cancer stem cells. Cancer Research 70 7294-7303. (doi:10.1158/0008-5472. CAN-09-3982)

Liao CP, Adisetiyo H, Liang M \& Roy-Burman P 2010b Cancer stem cells and microenvironment in prostate cancer progression. Hormones and Cancer 1 297-305. (doi:10.1007/s12672-010-0051-5)

Liao CP, Liang M, Cohen MB, Flesken-Nikitin A, Jeong JH, Nikitin AY \& Roy-Burman P 2010c Mouse prostate cancer cell lines established from primary and postcastration recurrent tumors. Hormones and Cancer 1 44-54. (doi:10.1007/s12672-009-0005-y)

Lin FC, Karwan M, Saleh B, Hodge DL, Chan T, Boelte KC, Keller JR \& Young HA 2014 IFN-gamma causes aplastic anemia by altering hematopoietic stem/progenitor cell composition and disrupting lineage differentiation. Blood 124 3699-3708. (doi:10.1182/blood2014-01-549527)
Markert EK, Mizuno H, Vazquez A \& Levine AJ 2011 Molecular classification of prostate cancer using curated expression signatures. PNAS 108 21276-21281. (doi:10.1073/pnas.1117029108)

Merlos-Suarez A, Barriga FM, Jung P, Iglesias M, Cespedes MV, Rossell D, Sevillano M, Hernando-Momblona X, da Silva-Diz V, Munoz P, et al. 2011 The intestinal stem cell signature identifies colorectal cancer stem cells and predicts disease relapse. Cell Stem Cell 8 511-524. (doi:10.1016/j.stem.2011.02.020)

Niu Y, Altuwaijri S, Yeh S, Lai KP, Yu S, Chuang KH, Huang SP, Lardy H \& Chang C 2008 Targeting the stromal androgen receptor in primary prostate tumors at earlier stages. PNAS 105 12188-12193. (doi:10.1073/pnas.0804701105)

Pfeiffer MJ \& Schalken JA 2010 Stem cell characteristics in prostate cancer cell lines. European Urology 57 246-254. (doi:10.1016/j. eururo.2009.01.015)

Prins GS \& Putz O 2008 Molecular signaling pathways that regulate prostate gland development. Differentiation 76 641-659. (doi:10.1111/j.1432-0436.2008.00277.x)

Schroder K, Hertzog PJ, Ravasi T \& Hume DA 2004 Interferon-gamma: an overview of signals, mechanisms and functions. Journal of Leukocyte Biology 75 163-189. (doi:10.1189/jlb.0603252)

Serio B, Selleri C \& Maciejewski JP 2011 Impact of immunogenetic polymorphisms in bone marrow failure syndromes. Mini-Reviews in Medicinal Chemistry 11 544-552. (doi:10.2174/138955711795843356)

Smith BA, Sokolov A, Uzunangelov V, Baertsch R, Newton Y, Graim K, Mathis C, Cheng D, Stuart JM \& Witte ON 2015 A basal stem cell signature identifies aggressive prostate cancer phenotypes. PNAS 112 E6544-E6552. (doi:10.1073/pnas.1518007112)

Stanley ER, Berg KL, Einstein DB, Lee PS, Pixley FJ, Wang Y \& Yeung YG 1997 Biology and action of colony - stimulating factor-1. Molecular Reproduction and Development 46 4-10. (doi:10.1002/(SICI)10982795(199701)46:1<4::AID-MRD2>3.0.CO;2-V)

Syed IS, Pedram A \& Farhat WA 2016 Role of sonic hedgehog (Shh) signaling in bladder cancer stemness and tumorigenesis. Current Urology Reports 17 11. (doi:10.1007/s11934-015-0568-9)

Tanner MJ, Welliver RC Jr, Chen M, Shtutman M, Godoy A, Smith G, Mian BM \& Buttyan R 2011 Effects of androgen receptor and androgen on gene expression in prostate stromal fibroblasts and paracrine signaling to prostate cancer cells. PLoS One 6 e16027. (doi:10.1371/journal.pone.0016027)

White AC \& Lowry WE 2015 Refining the role for adult stem cells as cancer cells of origin. Trends in Cell Biology 25 11-20. (doi:10.1016/j. tcb.2014.08.008)

Yamamoto Y, Loriot Y, Beraldi E, Zhang F, Wyatt AW, Nakouzi NA, Mo F, Zhou T, Kim Y, Monia BP et al. 2015 Generation 2.5 antisense oligonucleotides targeting the androgen receptor and its splice variants suppress enzalutamide-resistant prostate cancer cell growth. Clinical Cancer Research 21 1675-1687. (doi:10.1158/1078-0432.CCR14-1108)

Yoshida H, Hayashi S, Kunisada T, Ogawa M, Nishikawa S, Okamura H, Sudo T, Shultz LD \& Nishikawa S 1990 The murine mutation osteopetrosis is in the coding region of the macrophage colony stimulating factor gene. Nature 345 442-444. (doi:10.1038/345442a0)

Yu SQ, Yeh CR, Niu YJ, Chang HC, Tsai YC, Moses HL, Shyr CR, Chang CS \& Yeh SY 2012 Altered prostate epithelial development in mice lacking the androgen receptor in stromal fibroblasts. Prostate $\mathbf{7 2}$ 437-449. (doi:10.1002/pros.21445)

Zaidi MR \& Merlino G 2011 The two faces of interferon-gamma in cancer. Clinical Cancer Research 17 6118-6124. (doi:10.1158/10780432.CCR-11-0482)

Received in final form 4 February 2017

Accepted 6 February 2017 http://erc.endocrinology-journals.org

DOI: $10.1530 /$ ERC-16-0138
(C) 2017 Society for Endocrinology Printed in Great Britain
Published by Bioscientifica Ltd 